\title{
Performance of TaqMan probes for the detection of sexually transmitted infections in South African women
}

\begin{tabular}{|c|c|}
\hline \multicolumn{2}{|c|}{$\begin{array}{l}\text { Authors: } \\
\text { Nireshni Mitchev }^{1} \\
\text { Ravesh Singh }^{1,2} \\
\text { Nigel Garrett } \\
\text { Veron Ramsuran } \\
\text { Abraham J. Niehaus }^{3,4} \\
\text { Koleka P. Mlisana }\end{array}$} \\
\hline $\begin{array}{l}\text { Affiliations: } \\
{ }^{1} \text { Department o } \\
\text { Microbiology, } \\
\text { Laboratory Me } \\
\text { Medical Scienc } \\
\text { of KwaZulu-Na } \\
\text { South Africa }\end{array}$ & $\begin{array}{l}\text { f Medical } \\
\text { School of } \\
\text { dicine and } \\
\text { es, University } \\
\text { tal, Durban, }\end{array}$ \\
\hline $\begin{array}{l}{ }^{2} \text { Department } \\
\text { Microbiology, } \\
\text { Health Labora } \\
\text { Durban, South }\end{array}$ & $\begin{array}{l}\text { f Medical } \\
\text { National } \\
\text { tory Service, } \\
\text { Africa }\end{array}$ \\
\hline $\begin{array}{l}{ }^{3} \text { Centre for the } \\
\text { Programme of } \\
\text { in South Africa } \\
\text { South Africa }\end{array}$ & $\begin{array}{l}\text { AIDS } \\
\text { Research } \\
\text { Durban, }\end{array}$ \\
\hline $\begin{array}{l}{ }^{4} \text { Discipline of } \\
\text { Health Medicir } \\
\text { Nursing and } P \\
\text { University of } \mathrm{K} \\
\text { Durban, South }\end{array}$ & $\begin{array}{l}\text { Public } \\
\text { ne, School of } \\
\text { ublic Health, } \\
\text { waZulu-Natal, } \\
\text { Africa }\end{array}$ \\
\hline $\begin{array}{l}{ }^{5} \text { KwaZulu-Natz } \\
\text { Innovation an } \\
\text { Sequencing PI } \\
\text { School of Labc } \\
\text { Medicine and } \\
\text { Sciences, Univ } \\
\text { KwaZulu-Nata } \\
\text { South Africa }\end{array}$ & $\begin{array}{l}\text { ll Research } \\
\text { d } \\
\text { atform, } \\
\text { oratory } \\
\text { Medical } \\
\text { ersity of } \\
\text { l, Durban, }\end{array}$ \\
\hline $\begin{array}{l}{ }^{6} \text { Department } \\
\text { Affairs, Resear } \\
\text { Assurance, Nat } \\
\text { Laboratory Ser } \\
\text { South Africa }\end{array}$ & $\begin{array}{l}\text { f Academic } \\
\text { ch and Quality } \\
\text { tional Health } \\
\text { vice, Durban, }\end{array}$ \\
\hline $\begin{array}{l}\text { Corresponding } \\
\text { Abraham Nieh } \\
\text { abrahamnieha }\end{array}$ & $\begin{array}{l}\text { author } \\
\text { aus, } \\
\text { us@gmail.com }\end{array}$ \\
\hline Read online: & \\
\hline 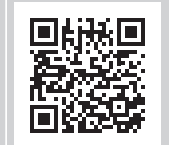 & $\begin{array}{l}\text { Scan this QR } \\
\text { code with your } \\
\text { smart phone or } \\
\text { mobile device } \\
\text { to read online. }\end{array}$ \\
\hline
\end{tabular}

Neisseria gonorrhoeae, Chlamydia trachomatis, Trichomonas vaginalis and Mycoplasma genitalium are the four main aetiologies of sexually transmitted infections responsible for vaginal discharge syndrome (VDS). Commercially available multiplex polymerase chain reaction (PCR) assays are expensive and generally not customisable. We evaluated a highly customisable singleplex PCR approach by testing it in parallel with the Anyplex ${ }^{\mathrm{TM}}$ II STI-7 detection assay in a cohort of South African women that presented with VDS between May 2016 and January 2017. Our multiple singleplex PCR strategy proved to be a simple, accurate, rapid, affordable and scalable option for diagnosing VDS.

Keywords: sexually transmitted infections; vaginal discharge syndrome; molecular diagnostics; validation; TaqMan.

\section{Introduction}

The World Health Organization estimates that approximately one million curable sexually transmitted infections (STIs) occur globally each day. ${ }^{1}$ Neisseria gonorrhoeae, Chlamydia trachomatis and Trichomonas vaginalis are the three most common pathogens causing STIs worldwide, with co-infection also common. ${ }^{1,2}$ Globally, as of 2016, there were approximately 86 million cases of gonorrhoea, 127 million cases of chlamydia and 156 million cases of trichomoniasis among $15-49$ year-olds, with estimated prevalence rates of $0.9 \%, 3.8 \%$ and $5.3 \%$ in women specifically. ${ }^{1,3}$ Such estimates are important for the effective prevention and control of STIs but are generally lacking for most low- and middle-income countries. ${ }^{4}$ Torrone et al. recently published a metaanalysis of data from African countries that highlights this point. ${ }^{4}$ Prevalence figures varied widely between studies and ranged from $1.4 \%$ to $15.2 \%$ for $N$. gonorrhoeae, $1.2 \%$ to $20.6 \%$ for C. trachomatis and $6.6 \%$ to $29.7 \%$ for T. vaginalis. ${ }^{4}$ The prevalence of most STIs is generally greater in certain high-risk populations such as those with a high prevalence of HIV co-infection and women aged $15-24$ years. ${ }^{4}$

Sexually transmitted infections and their complications are one of the top five reasons why females in low- and middle-income countries attend healthcare facilities. ${ }^{1,2}$ Although the majority of STIs are asymptomatic, asymptomatic STIs can increase the probability of transmission of HIV and other STIs, as well as have adverse effects on reproduction potential and maternal and newborn health. ${ }^{1,2,5,6}$

Syndromic management of STIs is widely practised and was introduced in South Africa in 1995.7,8 Unfortunately, due to its inability to effectively identify and treat a large number of individuals with asymptomatic infections, syndromic management has failed to decrease the prevalence of gonorrhoea and chlamydia in South Africa. ${ }^{78}$

Diagnosing the aetiology of most STIs using culture methods is notoriously difficult and can take several days to complete. Multiplex polymerase chain reaction (PCR) assays are currently the preferred diagnostic method used for identifying and subsequently managing both symptomatic and asymptomatic STIs in many well-resourced countries. ${ }^{9}$ Since PCR assays are not dependent on organism viability, they are often up to $20 \%-30 \%$ more sensitive than conventional phenotypic

Dates: Received: 07 Nov. 2019 | Accepted: 08 Jan. 2021 | Published: 31 Mar. 2021

How to cite this article: Mitchev N, Singh R, Garrett N, Ramsuran V, Niehaus AJ, Mlisana KP. Performance of TaqMan probes for the detection of sexually transmitted infections in South African women. Afr J Lab Med. 2021;10(1), a1124. https://doi.org/10.4102/ajlm. v10i1.1124

Copyright: @ 2021. The Authors. Licensee: AOSIS. This work is licensed under the Creative Commons Attribution License. 
methods and they can simultaneously detect multiple pathogens and also serve as point-of-care tests. ${ }^{9,10,11,12,13}$ Polymerase chain reaction also performs well on noninvasively obtained specimens like urine and selfcollected vaginal swabs. ${ }^{10}$

Our study aimed to evaluate the suitability of a highly customisable singleplex real-time PCR approach using commercially available TaqMan ${ }^{\circledR}$ probes (Thermo Fisher Scientific, Waltham, Massachusetts, United States) for the identification of $N$. gonorrhoeae, C. trachomatis, T. vaginalis and Myocoplasma genitalium in vaginal samples from our local population. The Anyplex ${ }^{\mathrm{TM}}$ II STI-7 detection assay (Seegene, Seoul, South Korea) was used as the comparator method. This widely used multiplex real-time PCR assay displays excellent sensitivity and specificity characteristics compared with other diagnostic tools. ${ }^{10}$

\section{Methods \\ Ethical considerations}

Women attending the Prince Cyril Zulu Communicable Disease Centre (Durban, South Africa) for STI care were approached and, if willing to participate, provided written informed consent for the study. Study data were collected, anonymised and managed using password-protected REDCap electronic data capture tools (Vanderbilt University, Nashville, Tennessee, United States), and stored on a secure server. This study was approved by the Biomedical Research Ethics Committee of the University of KwaZulu-Natal (study approval number: BE534/16).

\section{Samples}

As part of the Centre for the AIDS Programme of Research in South Africa 083 cohort study between May 2016 and January 2017, which was previously described in detail, women aged 18-40 presenting for STI care at a clinic in Durban were assessed for enrolment and participation. ${ }^{7,14}$ HIV-positive women, pregnant women and those engaging in sex work were excluded due to predetermined eligibility criteria. ${ }^{15}$ Participants consented to vaginal swab specimen collection for molecular testing. ESwab ${ }^{\mathrm{TM}}$ collection and transport kits (Copan Diagnostics, Brescia, Italy) were used as per the manufacturer's instructions.

\section{DNA extraction and polymerase chain reaction}

Collection swabs were vortexed for $30 \mathrm{~s}$ while inside their transport tubes, whereafter $500 \mu \mathrm{L}$ of the suspension was added to a $1.5 \mathrm{~mL}$ Eppendorf tube. This was followed by centrifugation and resuspension of the sediment in $200 \mu \mathrm{L}$ distilled water. After heating and sonication steps, $5 \mu \mathrm{L}$ of the resultant sample was added to $15 \mu \mathrm{L}$ pre-aliquoted master mix. For the TaqMan ${ }^{\circledR}$ probe assays, master mixes were prepared separately for each single target reaction in a 96-well plate. The Anyplex ${ }^{\mathrm{TM}}$ II STI-7 detection assay was used according to the manufacturer's specifications and was performed using a CFX96 real-time PCR system (BioRad,
Hercules, California, United States). ${ }^{10}$ TaqMan ${ }^{\circledR}$ probes were used in a singleplex format on the ABI ${ }^{\circledR} 7500$ real-time PCR instrument from Applied Biosystems (Thermo Fisher Scientific, Waltham, Massachusetts, United States).

\section{Data management and analysis}

Anyplex ${ }^{\mathrm{TM}}$ II STI-7 detection assay results were analysed and interpreted with Seegene Viewer software (Seegene, Seoul, South Korea). Contingency $2 \times 2$ tables were used to determine the sensitivity, specificity, positive predictive value and negative predictive value for each of the TaqMan ${ }^{\circledR}$ probes with Anyplex ${ }^{\mathrm{TM}}$ II STI-7 detection assay as the gold standard. ${ }^{10,16,17}$

\section{Results}

A total of 267 women were screened for STIs at an urban clinic in Durban, South Africa. Vaginal discharge $(n=106$; $39.7 \%$ ) was the most common symptom reported..$^{15}$ Vaginal swabs were available for molecular investigation from 250 (93.6\%) women. Two molecular assays were used in parallel to detect the presence of four sexually transmitted microorganisms implicated in vaginal discharge syndrome.

The yield obtained from 250 samples by each of the two methods ranged between $3.6 \%$ and $13.6 \%$ (Table 1). At least one of N. gonorrhoeae, C. trachomatis, T. vaginalis or M. genitalium was identified in $22.8 \%(57 / 250)$ of the study population. C. trachomatis was the most common organism found in co-infections and was present in $42 \%(5 / 12)$ of the N. gonorrhoeae, $25 \%(3 / 12)$ of the M. genitalium and $11 \%(1 / 9)$ of the T. vaginalis infections.

TaqMan ${ }^{\circledR}$ probe sensitivity ranged from $91.67 \%$ to $100 \%$, and specificity ranged from $98.74 \%$ to $100.00 \%$ (Table 2). Negative predictive values ranged from $99.08 \%$ to $100.00 \%$ and positive predictive values ranged from $90.00 \%$ to $100.00 \%$, except for M. genitalium $(78.57 \%)$.

Final results were available after $130 \mathrm{~min}$ and $180 \mathrm{~min}$ with the TaqMan ${ }^{\circledR}$ probes and Anyplex ${ }^{\mathrm{TM}}$ II STI-7 detection assay, respectively. This includes $45 \mathrm{~min}$ for DNA extraction and $15 \mathrm{~min}$ for results analysis.

\section{Discussion}

The prevalence of any of the main curable STIs, including syphilis and those caused by $N$. gonorrhoeae, C. trachomatis and T. vaginalis, in women in KwaZulu-Natal, South Africa was previously reported to be as high as $13 \% .{ }^{18}$ In our study, we observed the overall prevalence of STIs to be $22.8 \%$. Our prevalence data is not a true representation of the general population, because we recruited participants from a sexually active cohort of women that presented with symptoms to an STI clinic. The Xpert ${ }^{\circledR}$ CT/NG assay (Cepheid, Sunnyvale, California, United States) was previously used to investigate this cohort of samples. ${ }^{7}$ For the present study, we employed the Anyplex ${ }^{\mathrm{TM}}$ II STI-7 detection assay as the comparator, 
TABLE 1: Yield obtained with Anyplex ${ }^{\mathrm{TM}}$ II STI-7 detection assay and TaqMan ${ }^{\circledR}$ probes, from 250 vaginal swab specimens collected from patients attending Prince Cyril Zulu Communicable Disease Centre (Durban, South Africa) between May 2016 and January 2017.

\begin{tabular}{|c|c|c|c|c|c|c|c|c|}
\hline \multirow[t]{2}{*}{ Detection technique } & \multicolumn{2}{|c|}{ N. gonorrhoeae } & \multicolumn{2}{|c|}{ C. trachomatis } & \multicolumn{2}{|c|}{ T. vaginalis } & \multicolumn{2}{|c|}{ M. genitalium } \\
\hline & $n$ & $\%$ & $n$ & $\%$ & $n$ & $\%$ & $n$ & $\%$ \\
\hline Anyplex II STI-7 & 12 & 4.8 & 34 & 13.6 & 9 & 3.6 & 12 & 4.8 \\
\hline TaqMan probes & 11 & 4.4 & 33 & 13.2 & 10 & 4.0 & 14 & 5.6 \\
\hline
\end{tabular}

TABLE 2: Performance characteristics of TaqMan ${ }^{\circledR}$ probes for 250 vaginal swab specimens collected from patients attending Prince Cyril Zulu Communicable Disease Centre (Durban, South Africa) between May 2016 and January 2017.

\begin{tabular}{lcccc}
\hline TaqMan probes & Sensitivity (\%) & Specificity (\%) & $\begin{array}{c}\text { Positive } \\
\text { predictive } \\
\text { value (\%) }\end{array}$ & $\begin{array}{c}\text { Negative } \\
\text { predictive } \\
\text { value (\%) }\end{array}$ \\
\hline N. gonorrhoeae & 91.67 & 100.00 & 100.00 & 99.58 \\
C. trachomatis & 94.12 & 99.54 & 96.97 & 99.08 \\
T. vaginalis & 100.00 & 99.59 & 90.00 & 100.00 \\
M. genitalium & 91.67 & 98.74 & 78.57 & 99.58 \\
\hline
\end{tabular}

because the Xpert ${ }^{\circledR} \mathrm{CT} / \mathrm{NG}$ assay can identify $C$. trachomatis and $N$. gonorrhoeae, but not T. vaginalis and M. genitalium.

Sensitivity, specificity, positive predictive value and negative predictive value characteristics of the TaqMan ${ }^{\circledR}$ probes for the four investigated organisms compared well to the chosen reference method. The only exception was the low positive predictive value observed for M. genitalium. This deviation may be due to the small sample size and requires further investigation.

Except for certain antibiotic-resistant organisms, the STIs detected in our study can usually be treated with a course of antibiotics; however, if they remain undiagnosed and subsequently untreated, a range of serious health issues may follow. Complications include elevated HIV transmission rates, infertility as well as life-threatening ectopic pregnancy and stillbirths. ${ }^{19}$ A rapid, accurate and affordable STI diagnostic tool is therefore essential to identify and treat affected individuals. ${ }^{13}$

Molecular testing methods are advantageous over phenotypic testing methods due to the rapid availability of results. Polymerase chain reaction methodologies can also detect various predefined targets at the same time, including drugresistance determinants. Singleplex PCR methods offer some important advantages over multiplex methods, principally in terms of ease of optimisation, customisability and target quantification. New gene targets of interest can be added in a flexible way without the requirement of a full revalidation process of the existing targets. Our multiple singleplex PCR system can easily be adapted to diagnose various other clinical syndromes caused by bacterial, viral, fungal and parasitic microorganisms, including meningitis, blood stream infections, respiratory infections, diarrhoea, and urinary tract infections. SingleplexPCR systems allow target quantification, which has potential diagnostic, prognostic and clinical monitoring functions.

Turnaround times with our multiple singleplex PCR were 50 min shorter than with the multiplex method. The clinical impact of this time difference, when non-immediately lifethreatening infections are concerned, is probably insignificant.
Multiplex PCR methodologies are generally significantly more cost-effective than singleplex PCRs. However, this does not hold true when small numbers of molecular targets are considered. ${ }^{20}$ Costing of the four targets used in our testing system indicates a considerable cost saving of $\$ 15.27$ (United States dollars [USD]) per test, over the comparator method that is priced at $\$ 24.67$ USD per test. Affordability can be increased even further by using a 384-well reaction plate, making it an attractive option for high-throughput environments. With our system, we can easily adopt a workflow that is suitable for both research and clinical laboratories.

\section{Limitations}

Limitations of this study include the relatively small sample size and the low positivity rate obtained by both methodologies. Multiple other microorganisms and dual infections may also have been responsible for vaginal discharge syndrome in some women, but were not considered in this investigation.

\section{Conclusion}

The performance of four TaqMan ${ }^{\circledR}$ probes (Thermo Scientific) was assessed by comparison with the Anyplex II STI-7 detection assay. Our multiple singleplex real-time TaqMan ${ }^{\circledR}$ PCR approach proved to be highly sensitive and specific for the detection of $C$. trachomatis, $N$. gonorrhoeae, T. vaginalis and M. genitalium. This approach offers an accurate, cost-effective and scalable option for identifying these pathogens in our patient population.

\section{Acknowledgements}

The authors would like to acknowledge the AIDS Programme of Research in South Africa 083 STI study participants and staff at the National Health Laboratory Services (Inkosi Albert Luthuli Central Hospital, Durban, South Africa) and Centre for the AIDS Programme of Research in South Africa.

\section{Competing interests}

The authors declare that they have no financial or personal relationships that may have inappropriately influenced them in writing this article.

\section{Authors' contributions}

N.M., R.S. and K.P.M. conceptualised the study. K.P.M. was responsible for the overall supervision of the project and the acquisition of funding. N.M. and N.G. were responsible for project administration. N.M., R.S. and V.R. decided on the 
methodology and performed the laboratory investigations. N.M. curated all the data and the data analysis was done together with A.J.N. All authors participated in the writing of the manuscript.

\section{Sources of support}

This project was funded through a grant by the Department of Science and Technology and the National Research Foundation Centre of Excellence in HIV Prevention as well as a grant from the United States - South African Program for Collaborative Biomedical Research, through the South African Medical Research Council and the United States National Institutes of Health (grant number: AI116759).

\section{Data availability}

The authors confirm that the data supporting the findings of this study are available within the article or its supplementary materials.

\section{Disclaimer}

The views and opinions expressed in this article are those of the authors and do not necessarily reflect the official policy or position of any affiliated agency of the authors.

\section{References}

1. World Health Organization. Report on global sexually transmitted infection surveillance 2018 [homepage on the Internet]. 2019 [cited 2019 Jul 13]. Available
from: https://www.who.int/reproductivehealth/publications/stis-surveillancefrom: https:/

2. Tayoun ANA, Burchard PR, Caliendo AM, Scherer A, Tsongalis GJ. A multiplex PCR assay for the simultaneous detection of Chlamydia trachomatis, Neisseria PCR assay for the simultaneous detection of Chlamydia trachomatis, Neisseria
gonorrhoeae, and Trichomonas vaginalis. Exp Mol Pathol. 2015;98(2):214-218. gonorrhoeae, and Trichomonas vaginalis. Exp
https://doi.org/10.1016/j.yexmp.2015.01.011

3. Rowley J, Van der Hoorn S, Korenromp E, et al. Chlamydia, gonorrhoea, trichomoniasis and syphilis: Global prevalence and incidence estimates, 2016. Bull World Health Organ. 2019;97:548-562.

4. Torrone EA, et al. Prevalence of sexually transmitted infections and bacterial vaginosis among women in sub-Saharan Africa: An individual participant data meta-analysis of 18 HIV prevention studies. PLOS Med. 2018;15(6):e1002511. https://doi.org/10.1371/journal.pmed.1002511
5. Kaida A, Dietrich JJ, Laher F, et al. A high burden of asymptomatic genital tract infections undermines the syndromic management approach among adolescents and young adults in South Africa: Implications for HIV prevention efforts. BMC Infect Dis. 2018;18:499. https://doi.org/10.1186/s12879-018-3380-6

6. Workowski KA, Bolan GA, Centers for Disease Control and Prevention. Sexually transmitted diseases treatment guidelines, 2015. MMWR Recomm Rep. 2015; 64(RR-03):1-137.

7. Garrett NJ, Osman F, Maharaj B, et al. Beyond syndromic management: Opportunities for diagnosis-based treatment of sexually transmitted infections in low- and middle-income countries. PLoS One. 2018;13(4):e0196209. https://doi. org/10.1371/journal.pone.0196209

8. Garrett NJ, McGrath N, Mindel A. Advancing STI care in low/middle-income countries: Has STI syndromic management reached its use-by date? Sex Transm Infect. 2016;93(1):4-5. https://doi.org/10.1136/sextrans-2016-052581

9. Lee SJ, Park DC, Lee DS, Choe HS, Cho YH. Evaluation of Seeplex STD6 ACE detection kit for the diagnosis of six bacterial sexually transmitted infections. J Infect Chemother. 2012;18(4):494-500. https://doi.org/10.1007/s10156-011 0362-7

10. Choe HS, Lee DS, Lee SJ, et al. Performance of Anyplex II multiplex real-time PCR for the diagnosis of seven sexually transmitted infections: Comparison with currently available methods. Int J Infect Dis. 2013;17(12):e1134-e1140. https:// doi.org/10.1016/j.ijid.2013.07.011

11. Trembizki E, Costa AMG, Tabrizi SN, Whiley DM, Twin J. Opportunities and pitfalls of molecular testing for detecting sexually transmitted pathogens. Pathology. 2015;47(3):219-226. https://doi.org/10.1097/PAT.0000000000000239

12. Papp JR, Schachter J, Gaydos CA, Van Der Pol B. Recommendations for the laboratory-based detection of Chlamydia trachomatis and Neisseria gonorrhoeae - 2014. MMWR Recomm Rep. 2014;63(RR-02):1-19.

13. Unemo M. Current and future antimicrobial treatment of gonorrhoea - The rapidly evolving Neisseria gonorrhoeae continues to challenge. BMC Infect Dis. 2015;15:364. https://doi.org/10.1186/s12879-015-1029-2

14. Garrett N, Mitchev N, Osman F, et al. Diagnostic accuracy of the Xpert CT/NG and OSOM trichomonas rapid assays for point-of-care STI testing among young women in South Africa: A cross-sectional study. BMJ Open. 2019;9(2):e026888. https://doi.org/10.1136/bmjopen-2018-026888

15. Garrett N, Maharaj B, Osman F, et al. P4.115 High uptake of effective expedited partner therapy among young women with STIs and their partners in South Africa. Sex Transm Infect. 2017;93(Suppl 2):A233. https://doi.org/10.1136/sextrans2017-053264.610

16. Naaktgeboren CA, Bertens LCM, van Smeden $M$, et al. Value of composite reference standards in diagnostic research. BMJ. 2013;347:f5605. https://doi. org/10.1136/bmj.f5605

17. Alonzo TA, Pepe MS. Using a combination of reference tests to assess the accuracy of a new diagnostic test. Stat Med. 1999;18(22):2987-3003. https://doi. org/10.1002/(SICI)1097-0258(19991130)18:22\%3C2987::AID-SIM205\% 3E3.0.CO;2-B

18. Naidoo $S$, Wand $H$, Abbai NS, Ramjee G. High prevalence and incidence of sexually transmitted infections among women living in Kwazulu-Natal, South Africa. AIDS Res Ther. 2014;11:1. https://doi.org/10.1186/1742-6405-11-31

19. Centers for Disease Control and Prevention. Sexually transmitted disease surveillance report [homepage on the Internet]. 2016 [cited 2019 May 28]. Available from: https://www.cdc.gov/std/stats16/CDC 2016 STDS Report-for 508WebSep21_2017_1644.pdf

20. Deshpande A, White PS. Multiplexed nucleic acid-based assays for molecular diagnostics of human disease. Expert Rev Mol Diagn. 2012;12(6):645-659. https://doi.org/10.1586/erm.12.60 